\title{
The Effect of Immobilization Stress on Gastric Mucosal Histopathology in White Mice (Mus musculus) Male Swiss Webster Strain
}

\author{
Rizki Bunaya ${ }^{1}$, Ilhami Romus², Fajri Marindra ${ }^{3}$, Desby Juananda ${ }^{4}$ \\ ${ }^{1}$ Faculty of Medicine, Universitas Riau, Pekanbaru, Indonesia \\ ${ }^{2}$ Department of Pathology Anatomy, Faculty of Medicine, Universitas Riau, Pekanbaru, Indonesia \\ ${ }^{3}$ Department of Biochemistry, Faculty of Medicine, Universitas Riau, Pekanbaru, Indonesia \\ ${ }^{4}$ Department of Anatomy, Faculty of Medicine, Universitas Riau, Pekanbaru, Indonesia
}

Background: Immobilization stress is one method of stress induction on experimental animals. It affects the psychology and physical of experimental animals and is the recommended method for assessing changes in histological structure damage. The purpose of research was to analyze the effect of immobilization stress on gastric mucosal in mice.

Materials and Methods: This research was experimental with post-test-only control group design. Twenty white mice (Mus musculus) male Swiss Webster strains were used in this study and divided into 4 groups: control, immobilization stress 14 days, immobilization stress 21 days, immobilization stress 28 days. Mice were given immobilization stress using 50 cc syringes for 2 hours every day for 14 days, 21 days and 28 days. Gastric mucosal damage in mice was analyzed under a microscope with of 10 fields of view in each sample. Data were analyzed using the Kruskal Wallis test and Mann Whitney test.

Results: Gastric mucosal damage score were 0 in control, $1.42 \pm 0.265$ in 14 days, $1.82 \pm 0.265$ in 21 days, and $2.54 \pm 0.05$ in 28 days. There was significant difference between each group $(p<0.05)$, while the greatest damage was found in the 28 days group.

Conclusion: These result indicated that immobilization stress caused gastric mucosal damage and the degree of damage is in accordance with duration of stress.

Keywords: gastric mucosal, immobilization, stress

\section{Introduction}

Stress is a non-specific response from body against pressures from the external and internal environment called stressors. Stressors can trigger various physiological and behavioral responses in the body. ${ }^{1}$ General adaptation syndrome (GAS) by Hans Selye is concept of stress received in biomedical science. ${ }^{2-4}$ Chronic stress is known as a risk factor that has a large effect on process of psychological diseases and various diseases of the body such as heart disease, depression,

Date of submission: March 25, 2019

Last Revised: May 31, 2019

Accepted for publication: May 31, 2019

Corresponding Author:

Desby Juananda

Department of Anatomy

Faculty of Medicine, Universitas Riau

Jl. Diponegoro No.1, Pekanbaru 28133, Indonesia

e-mail: desbyjuananda@gmail.com

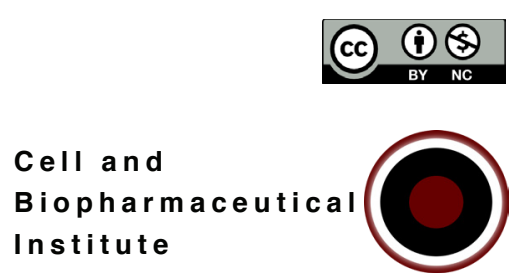


disorders of central nervous system and immunity and disorders of digestive system. ${ }^{5}$

Digestive system is regulated by the enteric nervous system (ENS). ENS has an important role in regulating the regulation and physiological functions of the gastrointestinal tract such as gastric secretion, motility, release of various neuropeptides and hormones, mucosal blood flow, and normal bacteria in the intestine. ${ }^{6.7}$ Interaction mechanism of the brain with the digestive system through some of pathways. The pathways is autonomic pathway system (ANS) and hypothalamic pituitary-adrenal axis (HPA) pathway, or known as the brain-gut axis (BGA). ${ }^{6}$ Stress exposure can cause regulatory disruption in the BGA which results in disruption of the physiological function of digestive system regulated by the BGA pathway which increased gastric secretion, decreased blood flow to the mucosal, reduced ability to proliferate and regenerate damaged mucosal, and motility changes, can cause erosion to mucous ulcers in the stomach. ${ }^{7,8}$

Stress induction methods in experimental animals consist of various methods such as footshock, corticosterone, and immobilization (restraint). ${ }^{910}$ The method of immobilization or restraint is one method to induce physical stress and psychological stress in experimental animals by limiting the movement of experimental animals. This method is recommended because it is very easy, without giving pain and does not cause weakness in animal testing. Immobilization stress is the method most often used to induce acute and chronic stress in experimental animals. ${ }^{10}$ Induction immobilization stress is also more recommended to assess damage of histological structures because it can explain and describe changes in histological structure of the gastric and intestinal mucosa. ${ }^{11}$ Based on the studied, immobilization stress method was interesting to use in this study. The aims of this study to know the effect of immobilization stress on gastric mucosa in mice.

\section{Materials and methods}

This was experimental research conducted in the Laboratory of Biochemistry, Faculty of Medicine, Universitas Riau and had passed the ethical review with No. 334/UN.19.5.1.1.8/ UEPKK/2017. The subjects were 20 white mice (Mus musculus) male Swiss Webster strains aged 10-12 weeks, with body weight of 25-35 grams, which have been declared healthy were indicated by the appearance of the condition of hair that is not dull, fall out, or bald, and was active.
Mice were divided into 4 groups consisting of the control group, 14 days group, 21 days group and 28 days group. The minimum number of samples were calculated with Resource Equation Method formula ( $\mathrm{n}=5$ for each group). Immobilization stress was given for 14 days, 21 days and 28 days according to the treatment group.

\section{Induction of Immobilization Stress}

Stress induction of immobilization was using a vessel in the form of a $50 \mathrm{cc}$ syringe that had been modified, so that the air circulation of mice was well maintained. The immobilization stress was given for 2 hours every day at 9:00 a.m. until 11:00 a.m. After stress induction was given, the mice was returned to the cage. Food and water intake was given by ad libitum. Mice were terminated on the last day of induction immobilization stress using an anesthetic process, then take the gastric tissue through surgical process.

\section{Sample Preparation}

Gastric tissue slides was made in the anatomic pathology laboratory in Pekanbaru. The method of slide preparation was using standard operasional procedure of the anatomic pathology laboratory.

\section{Mucosal Damage Evaluation}

The slides were viewed under a microscope with a $40 \mathrm{x}$ magnification of 10 view fields in each sample. Determination of the degree of gastric mucosal damage was referring to the Barthel Manja score, with grade 0 meant that there was no pathologycal changes, grade 1 meant that the epithelium desquamation was characterized by epithelial element release, grade 2 meant that erosion was characterized by the release of superficial epithelial elements, and grade 3 meant that the ulceration was characterized by loss of epithelial elements.

\section{Data Analysis}

The data obtained was processed and tested using the Kruskal-Wallis test and then using the Mann-Whitney test.

\section{Results}

Histopathological damage of gastric mucosal in mice was assessed using Barthel Manja score. The score of mucosal damage of the four groups presented in Figure 1, meanwhile the degree of gastric mucosal damage was shown in Figure 2.

The results of the comparison test between groups showed that there were significant differences between each group ( $p=0.001)$. Post Hoc analysis (Mann-Whitney 


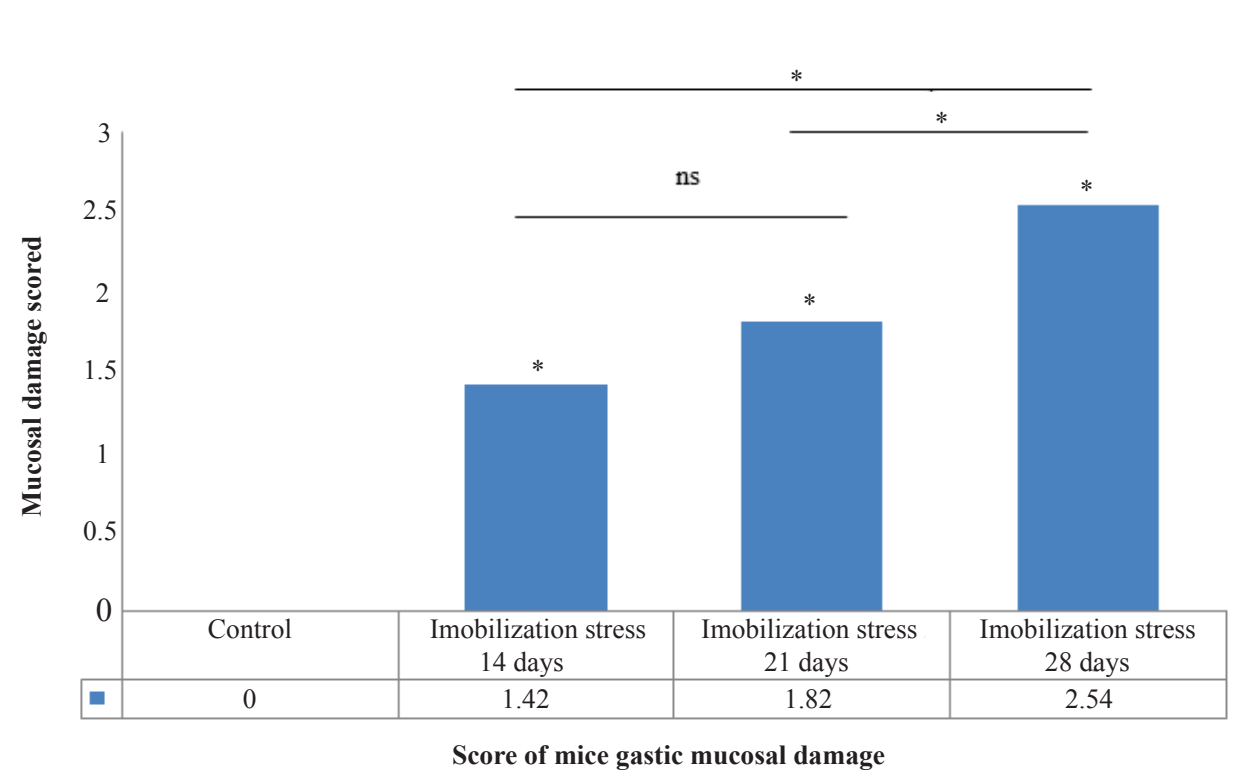

Figure 1. Comparison of gastric mucosal damage between groups. The highest average score in histopathological images of gastric mucosal (Mus musculus) was found in the 28 days group while the lowest was in the control group. $\mathrm{n}=5,{ }^{*} p<0.05$, ns=not significant; analized with Man Whitney test.

test) showed that there were significant differences between the control group and the 14 days stress group $(p=0.005)$, the control group with 21 days stress $(p=0.005)$, the control group with 28 days stress $(p=0.005)$, the group 14 days stress with 28 days stress group ( $p=0.009), 21$ days stress group with 28 days stress group $(p=0.012)$, while in the 14 days stress group with 21 days stress group $(p=0.295)$ it was not significant.

\section{Discussion}

Gastric mucosal damage caused by immobilization stress is seen in histopathological images. In the 14 days stress group, 21 days stress and 28 days stress found desquamation of epithelial cells (grade 1) characterized by epithelial element release, and epithelial cell erosion (grade 2) characterized by the release of superficial epithelial elements, and epithelial ulceration (grade 3 ) namely the loss of epithelial elements. In the 14 days stress group dominated by grade 1 gastric mucosal damage, the 21 days stress group was dominated by grade 2 gastric mucosal damage and the 28 days stress group dominated by grade 3 gastric mucosal damage. This indicates that gastric mucosal damage depends on the duration of stress induction immobilization was given.

Changes in the degree of gastric mucosal damage between treatment groups 14 days and 21 days were not significant $(p>0.05)$. This is because the duration of stress between the two groups is not so different, that there are no significant differences. The body's adaptation of stress exposure did not last long, this was proven by the level of damage between the groups of 21 days and 28 days found significantly $(p<0.05)$. the body's adaptation to stress decreases due to continuous exposure of stress up to 28 days. ${ }^{12}$ The immobilization stress causes a disruption in the digestive system. Mast cells will receive stress signals transmitted through the brain-gut axis which will then release various neurotransmitters and inflammatory mediators such as 5-hydroxytryptamine (5-HT), substance P (SP), calcitonin gene-related peptide (CGRP), C-reactive protein (CRP), cholecystokinin (CCK), nitric oxide (NO), norepinephrine (NE) and vasoactive intestinal polypeptide (VIP). These peptides caused physiological disorders and motility in the digestive system. Stress also affects the mucous blood flow to the stomach, the gastric mucosal blood flow will decrease and caused impaired on microcirculation of blood flow in the gastric mucosal. ${ }^{13}$

The impaired of microcirculation will cause species oxygen reactive substances (ROS) such as superoxide anions, hydrogen peroxide, hydroxyl radicals, hypochlorous acid, chloramine, and lipid hydroperoxide to be produced quickly and continuously in the body. An increased of ROS will induce inflammation of the gastrointestinal tract by stimulating polymorphonuclear neutrophilic leukocyte (PMN) which will cause damage and process of epithelial 

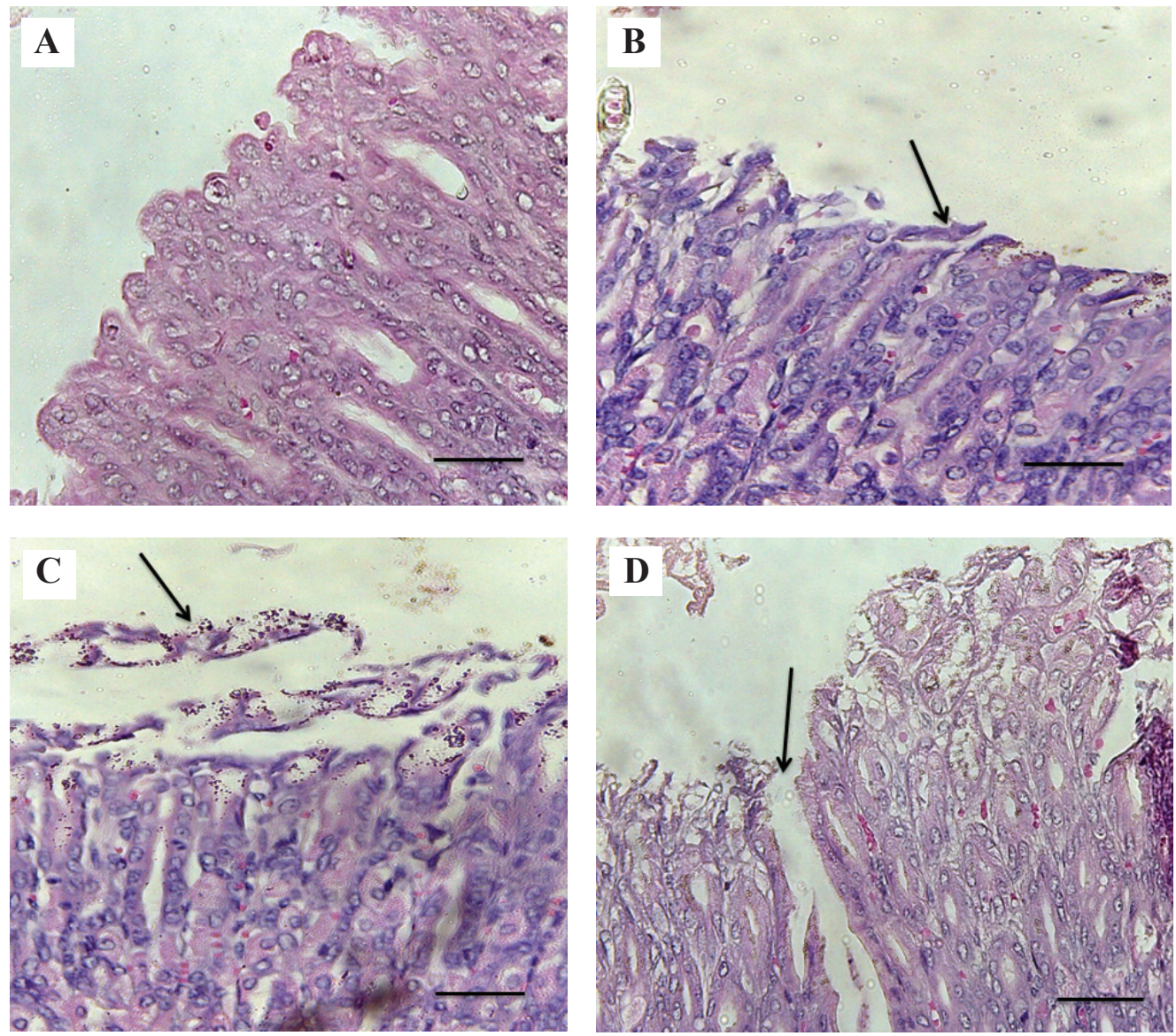

Figure 2. Degree of gastric mucosal damage. A: a normal grade gastric mucosal histopathology (grade 0); B: a histopathologic picture of the gastric mucosal, the arrow indicate desquamation of epithelial cells (grade 1); C: a histopathological picture of the gastric mucosa, the arrow indicate erosion of epithelial cells (grade 2); D: a histopathological picture of gastric mucosal, the arrow indicateulcerated gastric mucosal (grade 3). H\&E staining, black bar $=40 \mu \mathrm{m}$.

necrosis and ulceration of the gastric mucosal. Induction of stress continuously will cause impaired with the protection factors of gastric mucosal such as NO and prostaglandin I2 (PGI2). NO and PGI2 or prostacyclin which acts as vasodilators and maintains the circulation of mucous blood flow, protecting the gastric mucosal from damage. NO and PGI2 protecting endothelial cells and inhibit platelet and leukocyte adhesion to microvascular resulting in preventing of microiskemia. ${ }^{14}$

\section{Conclusion}

These result indicated that immobilization stress for 14 days, 21 days, and 28 days on mice caused gastric mucosal damage and the degree of damage is in accordance with duration of stress. Where 28 days group showed the highest gastric mucosal damage compared to the other groups.

\section{Acknowledgements}

This study was supported by grant from the Budget Implementation List/Daftar Isian Pelaksanaan Anggaran (DIPA) of Faculty of Medicine, Universitas Riau.

\section{References}

1. Garcia C, Melo-thomas L, Spadari-bratfisch RC, Ortolani D. Stressinduced endocrine response and anxiety: the effects of comfort food in rats. Stress. 2014; 17(3): 211-8.

2. Kranner I, Minibayeva F V, Beckett RP, Seal CE. What is stress? Concepts, definitions and applications in seed science. New Phytol. 2010; 188(3): 655-73.

3. Marten F. The Mediating Effect of Eustress and Distress on the Relation between the Mindset Towards Stress Health [Essay]. Enschede: University of Twente; 2017.

4. Koolhaas JM, Bartolomucci A, Buwalda B, Boer SF De, Flügge G, Korte SM, et al. Neuroscience and biobehavioral reviews stress revisited: A critical evaluation of the stress concept. Neurosci Biobehav Rev. 2011; 35(5): 1291-301. 
5. Armario A. Studying Chronic Stress in Animals: Purposes, Models and Consequences. New Jersey: John Wiley \& Sons Ltd; 2015.

6. Konturek PC, Brzozowsk T, Konturek SJ. Stress and the gut: pathophysiology, clinical consequences, diagnostic approaach and treatment options J Physiol Pharmacol. 2011; 62(6): 591-9.

7. Foster JA, Rinaman L, Cryan JF. Stress \& the gut-brain axis: Regulation by the microbiome. Neurobiol Stress. 2017; 7: 124-36.

8. Plummer MP, Blaser AR, Deane AM. Stress ulceration: prevalence, pathology and association with adverse outcomes. BioMed Central. 2014; 18(2): 213. doi: 10.1186/cc13780.

9. Reber SO, Slattery DA. Editorial: Using stress-based animal models to understand the mechanisms underlying psychiatric and somatic disorders. Front Psychiatry. 2016; 7: 192. doi: 10.3389/ fpsyt.2016.00192.

10. Brainova I. Effects of immobilization stress on distribution of nadph-d reactive neurons in rat's paraventricular nucleus. IJTRA. 2015; 3(6): 150-3.

11. Altayeb ZM, Salem MM. Light and electron microscopic study on the effect of immobilization stress on adrenal cortex of adult rats and possible ameliorative role of vitamin E. Neuroscience. 2017; 1(1): 44-56.

12. Koolhaas JM, Boer SF, Buwalda B. Stress and adaptation. Toward ecologically relevant animal model. Physiol Sci. 2006; 15(3): 10912.

13. Wang Y, Liu J, Yang ZY. Effects of intestinal mucosal blood flow and motility on intestinal mucosa. World J Gastroenterol. 2011; 17(5): 657-61.

14. Kawano S, Tsuji S. Role of mucosal blood flow: a conceptional review in gastric mucosal injury and protection. J Gastroenterol Hepatol. 2000; 15(S1): D1-6. doi: 10.1046/j.1440-1746.2000.02142.x. 